\title{
Pengelolaan Central Diabetes Insipidus Pasca Cedera Kepala Berat
}

\author{
Bona Akhmad Fithrah*), Marsudi Rasman ${ }^{* *}$, Siti Chasnak Saleh ${ }^{* * *}$ \\ *),Departemen Anestesiologi \& Terapi Intensif Rumah Sakit Mayapada Lebak Bulus Jakarta, ${ }^{* *}$ Departemen \\ Anestesiologi \& Terapi Intensif Fakultas Kedokteran Universitas Padjadjaran-RSUP Dr. Hasan Sadikin Bandung, \\ ${ }^{* * *}$ Departemen Anestesiologi \& Reanimasi Fakultas Kedokteran Universitas Airlangga-RSUD Dr. Soetomo \\ Surabaya
}

\begin{abstract}
Abstrak
Cedera otak traumatika adalah salah satu penyebab kematian dan kesakitan tersering pada kelompok masyarakat muda. Hasil akhir dari cedera kepala berat dapat menyebabkan gangguan kognitif, perilaku, psikologi dan sosial. Salah satu konsekuensi dari cedera kepala berat adalah terjadinya disfungsi hormonal baik dari hipofise anterior maupun posterior. Angka kejadian disfungsi hormonal ini sekitar 20-50\%. Salah satu yang paling menantang dan sering terjadi adalah diabetes insipidus (DI) dan Syndrome inappropriate antidiuretic hormone (SIADH). Angka kejadian diabetes insipidus pasca cedera kepala diduga sebesar 1-2,9\% dengan berbagai tingkatannya. Pada beberapa kasus bersifat sementara tapi beberapa kasus terjadi bersifat menetap. Pada laporan kasus ini akan dibawakan sebuah kasus diabetes insipidus pasca cedera kepala berat. Pasien mengalami cedera kepala berat, hingga dilakukan decompressive craniectomi dan trakeostomi. Untuk perawatan lanjutan pasien dirujuk ke Jakarta. Saat menjalani terapi lanjutan ini pasien terdiagnosis diabetes insipidus Pada kasus ini diabetes insipidus tidak timbul langsung setelah cedera kepala tetapi baru timbul lebih kurang satu bulan setelah cedera kepala. Diabetes insipidus dikelola dengan menggunakan desmopressin spray dan oral disamping mengganti cairan yang hilang. Pada kasus ini desmopressin sempat di stop sebelum akhirnya diberikan terus menerus dan pasien diterapi sebagai diabetes insipidus yang menetap.
\end{abstract}

Kata kunci: cedera kepala berat, disfungsi neurohormonal, diabetes insipidus

JNI 2019;8 (2): 99-104

\section{Managing Central Diabetes Insipidus in Post Severe Head Injury Patient}

\begin{abstract}
Traumatic brain injury is the cause of mortality and morbidity in society mostly in male-young generation. The last outcome of traumatic brain injury might be deficit in cognitive, behavioral, psychological and social. the consequences of traumatic brain injury might be hormonal disfunction from anterior and posterior pituitary. The incidence around $20-50 \%$. The most challenging problem is diabetes insipidus (DI) and syndrome of inappropriate antidiuretic hormone (SIADH). The incident of post traumatic diabetes insipidus around 1-2,9\% with several degree. In certain case its only occurred transiently but some report it could be permanent. In this case report will find one case post traumatic diabetes insipidus. This pasien had severe traumatic brain injury and underwent decompressive craniectomy and tracheostomy. For further therapy patient was referred to Jakarta. In this further treatment patient diagnosed with diabetes insipidus. Diabetes insipidus doesn't occurred since the first day of injury but occurred almost one month after. Diabetes insipidus managed with desmopressin spray and oral beside replace water loss. For a few days desmopressin stop but diabetes insipidus occurred again so desmopressin given daily both spray and oral and the patient had therapy as diabetes insipidus permanent.
\end{abstract}

Key words: traumatic brain injury, neuroendocrine disfunction, diabetes insipidus.

JNI 2019;8 (2): 99-104 


\section{Pendahuluan}

Angka kejadian cedera kepala diperkirakan sebesar 235/100.000 pertahun berdasarkan data epidemiologi yang terjadi di tiga belas negara Eropa. Di Amerika Serikat cedera kepala menyebabkan masuknya 300.000 pasien ke rumah sakit per tahunnya. Di Inggris dan Wales tiap tahun 1,4 juta pasien masuk ke unit gawat darurat. Sebagian besar angka angka ini mengenai usia dewasa muda dan produktif. Menyebabkan berbagai konsekuensi seperti hilangnya kemandirian, tidak dapat bekerja dan kualitas hidup yang buruk. ${ }^{1}$ Cedera otak traumatika ialah kelainan non degeneratif, non kongenital pada otak yang disebabkan oleh kekuatan mekanis yang menyebabkan disfungsi neurologis yang sifatnya sementara maupun menetap. Berbeda dengan istilah cedera kepala yang bersifat non spesifik, yang lebih bermakna cedera pada salah satu bagian kepala seperti wajah, kulit kepala maupun calvarium yang dapat terkait maupun tidak dengan cedera otak traumatika. ${ }^{2}$

Lebih kurang 50\% dari cedera otak traumatika terkait dengan kendaraan bermotor. Terjatuh dari ketinggian hanya menempati urutan kedua $(30 \%)$. Sedangkan trauma akibat kekerasan fisik menempati urutan ketiga dengan estimasi sekitar $(20 \%) .{ }^{2}$ Komplikasi dari cedera otak traumatika tidak sebatas pada yang bersifat neurologis saja. Komplikasi dari saluran cerna seperti disfungsi hepar, dysphagia, gastroparesis yang semuanya berujung pada masalah nutrisi menempati urutan pertama dengan angka $50 \%$, komplikasi kardiovaskular seperti hipertensi deep vein thrombosis (DVT), emboli pulmonal sekitar $30 \%$, masalah pada system musculoskeletal seperti patah tulang. sekitar $30 \%$ sedangkan komplikasi neuroendocrine sendiri memiliki angka sekitar $40 \%$. ${ }^{2}$ Komplikasi neuroendocrine bermanifestasi pada pasien cedera otak traumatika sangat bervariasi. Ada yang timbul segera setelah kejadian hingga bertahun tahun setelah cedera otak terjadi. Bahkan dilaporkan hingga menyebabkan komplikasi yang bersifat kronik dan menetap. ${ }^{2}$ Dampak cedera otak traumatika pada neuroendocrine adalah terjadinya gangguan hormon hipofisis, baik hipofisis anterior maupun posterior. Angka kejadiannya diduga sekitar 20$50 \%$ dengan berbagai tingkatan kerusakannya. ${ }^{2}$ laporan pertamatentang disfungsihormonhipofisis pasca trauma sendiri telah ada sejak tahun 1918 yang disusun oleh Cyran. ${ }^{3}$ Sebagian besar kasus disfungsi hormon pasca cedera otak traumatika adalah terkait dengan elektrolit khususnya natrium dan air. Gangguan pada elektrolit dan air ini adalah penyumbang morbiditas dan mortalitas terbesar. ${ }^{4}$ Sebagian besar kasus elektrolit dan air ini yang terjadi adalah central diabetes insipidus (DI) dan syndrome of inappropriate antidiuretic hormone secretion (SIADH). Dua kelainan ini yang sering menjadi momok bagi pasien cedera kepala berat. ${ }^{5}$ cedera otak traumatika berat dapat secara langsung maupun tidak langsung memicu terjadinya disfungsi dari hipotalamus yang mensekresikan anti diuretik horman. ${ }^{5}$ atau dapat juga mempengaruhi kelenjar hormon hipofisis posterior yang menyebabkan terjadianya diabetes insipidus. ${ }^{5}$ Diabetes insipidus yang terjadi juga bersifat sementara dan sangat jarang terjadi menetap/permanen. ${ }^{4}$

Hubungan antara cedera otak traumatika dengan diabetes insipidus adalah sebuah komplikasi yang langka dengan angka insiden sekitar $<1 \%$. Sebuah studi retrospektif juga menyatakan hal yang sama bahwa kejadian diabetes insipidus pasca cedera otak traumatika adalah kecil $(2,9 \%) .{ }^{2}$ Pada laporan kasus ini akan dibawakan sebuah kasus diabetes insipidus pasca cedera otak traumatika berat yang terjadi pada seorang mahasiswa yang mengalami kecelakaan lalu lintas.

\section{Kasus}

\section{Anamnesis}

Sebelas hari sebelum masuk rumah sakit di Jakarta pasien mengalami kecelakaan lalu lintas di Jember, Jawa Timur, dengan GCS preoperatif E1M1V3, dilakukan resusitasi dan ditegakkan diagnosis dengan cedera kepala berat. Pada pasien dilakukan decompresi craniektomi. Pasca operasi dilakukan barbiturate coma dan ventilasi mekanik. Seminggu kemudian pada pasien dilakukan trakeostomi. Setelah sebelas hari di rawat di Jember pasien dirujuk ke rumah sakit Mayapada di Jakarta untuk melanjutkan 
perawatan. GCS saat diterima di rumah sakit Mayapada adalah E3M5Vtracheostomi. Saat di rumah sakit Mayapada dilakukan tindakan cranioplasty dan pemasangan ORIF pada fraktur mandibulanya. Setelah operasi pasien dirawat di ruangan biasa. Pada pasien belum ditemukan adanya gejala perubahan pada elektrolit ataupun produksi urinnya. Lebih kurang satu bulan setelah kecelakaan lalu lintas produksi urin pasien mulai meningkat secara bermakna.

\section{Pemeriksaan Fisik (sudah dalam perawatan)}

Keadaan umum tampak sakit berat, GCS E4M5Vtracheostomi, leher terpasang kanul trakeostomi, central vein catether (CVC) terpasang pada subclavia kanan, tekanan darah 120/80 $\mathrm{mmHg}$, frekuensi, nadi105x/m, frekuensi pernapasan 20x/m Saturasi 98\% dengan udara ruangan. Jantung BJ I-II normal, murmur -, gallop - Paru bronchial, Rh-/-, wh-/-.

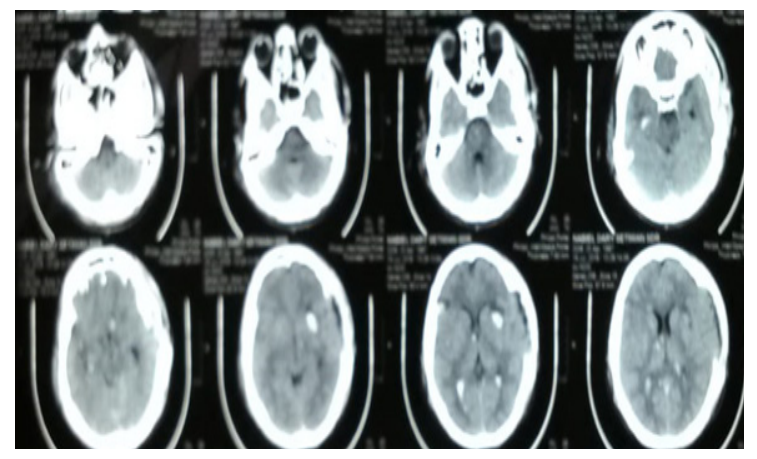

Gambar 1. CT pertama dari RSUD Jember

\section{Pemeriksaan Penunjang}

Laboratorium

Hematologi 12,1/36/9,6/333.000 SGOT/ SGPT $11 / 10 \quad$ Ur/Cr $14 / 0,63 \quad$ GDS 88 PT/ Aptt 10,3(10,5)/27,5(25,4) Alb 4,2 elektrolit 141/4,4/106. Rontgen thoraks: Jantung paru tidak ada kelainan. EKG irama sinus tdk adaST depresi/ elevasi, tidak ada LVH/RVH, MRI/CT Scan

\section{Pengelolaan Anestesi}

Riwayat pengelolaan anestesi pada pasien ini sangat panjang. Dimulai dari cedera otak traumatika yang dialami dengan diagnosis diffuse axonal injury. Saat itu tingkat kesadaran pasien E1M1V3. Pasien diintubasi di IGD RSUD Jember dan dilanjutkan dengan tindakan kraniektomi

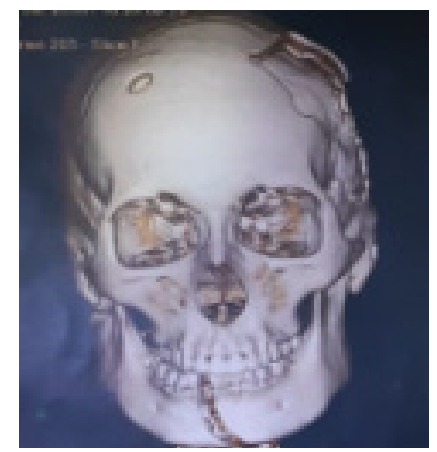

Gambar 2. Foto fraktur mandibula
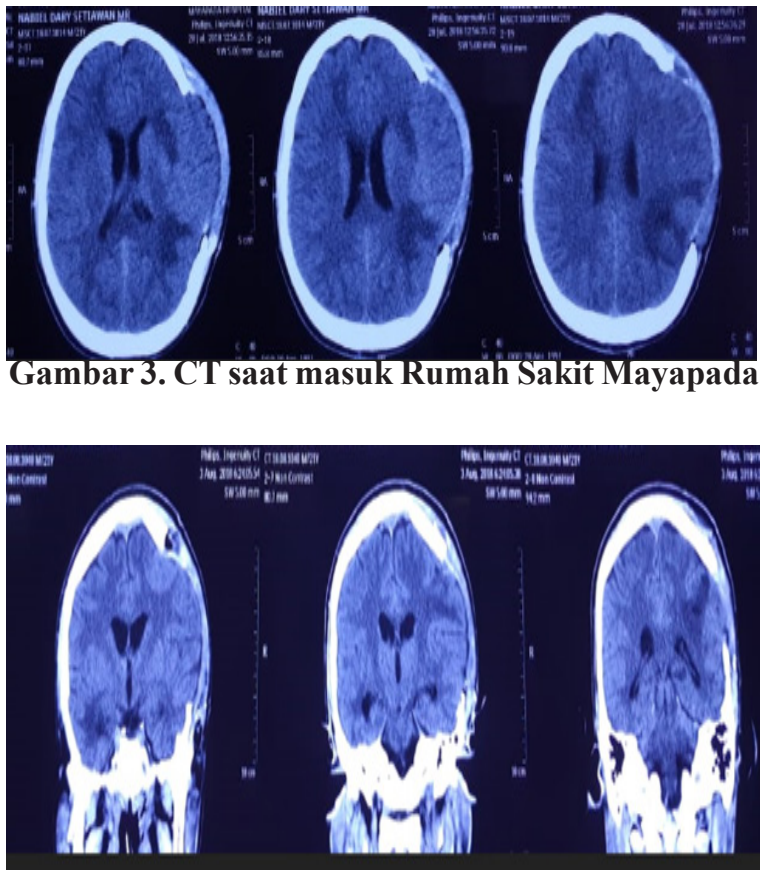

Gambar 4. CT Saat masuk Rumah Sakit Mayapada

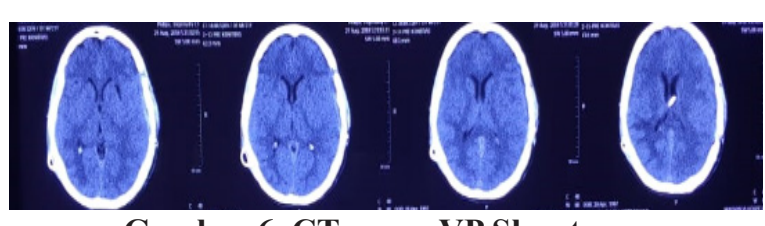

Gambar 6. CT pasca VP Shunt

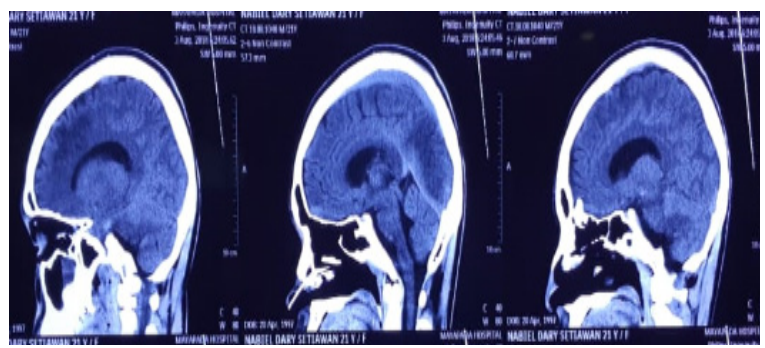

Gambar 7. CT scan terakhir sebelum pasien direncanakan pulang 


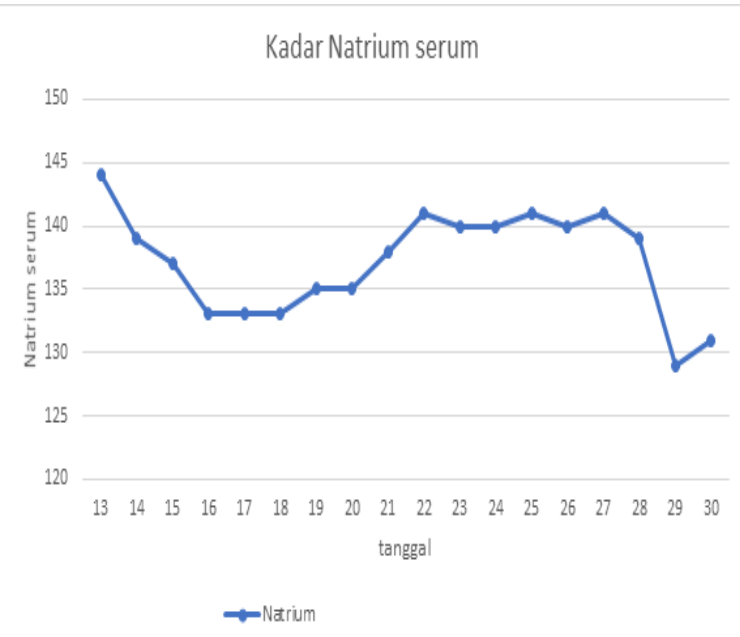

Grafik 1. Grafik Kadar Natrium Serum

dekompresi. Pasca operasi pasien di trakeostomi dan dirawat di ICU. Pada hari ke sebelas pasien dirujuk ke Jakarta. GCS pasien saat di terima di RS Mayapada adalah E3M5Vt dan hemodinamik stabil. Di Jakarta pasien dilakukan prosedur $v p$ shunt, cranioplasty dan pemasangan fiksasi internal untuk fraktur mandibulanya. Pasien dirawat di High Care Unit (HCU) selama empat hari. Selanjutnya pasien dirawat di ruangan biasa untuk persiapan home care. Lebih kurang tiga puluh hari setelah pertama kali kecelakaan, produksi urin pasien meningkat hingga $4 \mathrm{cc} /$ $\mathrm{kgbb} / \mathrm{jam}$ selama hampir $24 \mathrm{jam}$. Saat itu pasien masih dirawat di ruangan biasa dan terpasang kateter urin. Pasien dipindahkan ke HCU untuk monitoring lebih ketat kondisinya. Saat dipindahkan produksi urin pasien mencapai 8,7 $\mathrm{cc} / \mathrm{kgbb} / \mathrm{jam}$.

Pada pasien ditegakkan diagnosis central diabetes insipidus. Dan dilakukan terapi dengan mengganti cairan yang keluar dan memberikan desmopressin spray. Urin yang keluar diganti dengan cairan ringer fundin. Pola penggantian adalah dengan mengganti sebesar $60 \%$ dari total urin yang keluar selama 3 jam. Penggantian akan dilakukan pada 3 jam berikutnya. Setelah tiga jam dihitung kembali urinnya dan akan diganti pada tiga jam berikutnya. Ini dilakukan terus menerus hingga produksi urin kembali normal. Desmopressin adalah senyawa sintetis dari vasopressin. Desmopressin spray diberikan bertahap. Dari mulai 1x1 spray (1 spray: $10 \mathrm{mcg}$ )

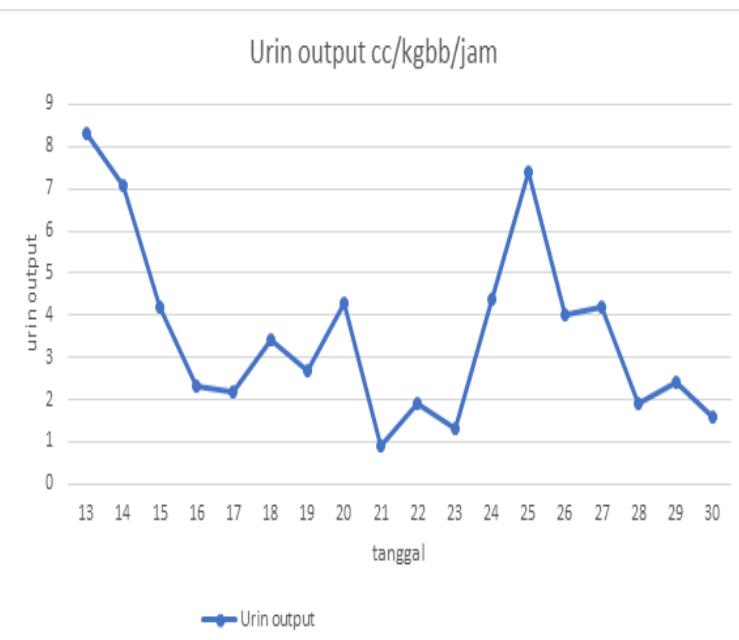

Grafik 2. Grafik Urin Out Put (cc/kgbb/jam)

Produksi urin yang terjadi terlihat naik turun dan tidak bisa lepas dari desmopressin karena bila desmopressin diturunkan maka urin akan kembali meningkat hingga akhirnya desmopressin diberikan secara terus menerus dan saat akan home care diganti dengan per oral sebesar $3 \times 0 .{ }^{1}$ mg. Pasien pulang dengan GCS E3M5Vtrach. Diabetes insipidus terkendali setelah hari ke tujuh belas sejak tegak diagnosis diabetes insipidus. Total lama perawatan pasien ini di Rumah Sakit Mayapada adalah dua bulan

\section{Pembahasan}

Insiden central diabetes insipidus pada pasien neuroanestesi bervariasi. Pada pasien pasca craniotomy sekitar $6,7 \%$, pada pasien pasca operasi aneurisma sekitar $4 \%$ dan pada pasien pasca cedera otak traumatika sekitar $2 \%{ }^{6}$ Yang harus diingat walaupun angka kejadiannya kecil tetapi memiliki angka morbiditas dan mortalitas yang besar $(74 \%){ }^{8}$ Karena itu yang harus jadi panduannya adalah kapan harus dipertimbangkan kemungkinan diagnosis dari central diabetes insipidus ini terjadi pada pasien. Onset dari central diabetes insipidus juga bervariasi ada yang menyebutkan onset bisa terjadi dini yaitu segera setelah cedera otak traumatika, satu bulan setelah cedera kepala bahkan hingga tiga bulan setelah cedera kepala. ${ }^{2,9}$ Pada pasien ini central diabetes insipidus terjadi setelah satu bulan pasca cedera otak traumatika. Polyuria adalah tanda pertama yang harus dipertimbangkan untuk kasus 
central diabetes insipidus. Terutama bila polyuria terjadi lebih kurang tiga hari hingga satu bulan setelah cedera otak traumatika. ${ }^{79}$ Walaupun tanda polyuria ini masih harus disaring lagi dengan kemungkinan seperti penggunaan mannitol, hiperglikemi atau akibat penggunaan diuretika lain. ${ }^{7}$ Peran dari pemeriksaan osmolalitas urin akan mampu membedakannya. Tanda berikutnya yang harus menjadi pertimbangan adalah tanda hypernatremia. Sedangkan tanda lain seperti polydipsia atau haus biasanya tidak akan terlihat karena tertutupi oleh kondisi lainnya seperti pasien sudah dalam trakeostomi, masih terintubasi ataupun pasien penurunan kesadaran. ${ }^{7,9}$

Penggunaan imaging untuk membantu menegakkan diagnosis central diabetes insipidus tidak akan membantu banyak. Kecuali terjadi kerusakan langsung pada kelenjar hipofisisnya. ${ }^{5}$ Pada kasus ini gambaran imaging tidak ada yang khusus selain gambaran edema cerebri. Pada pasien ini onset terjadi diabetes insipidus lebih kurang hari ke-28 sejak cedera otak traumatika. Penegakkan diagnosis dari kasus ini berdasarkan tanda polyuria yang terjadi. Saat yang bersamaan pasien sudah tidak memakai obat-obatan yang memicu peningkatan produksi urin seperti mannitol, gula darah dalam kedaan normal dan tidak ada penggunaan diuretik. Pada pasien ini tidak dilakukan pemeriksaan osmolalitas urin karena hanya satu kelainan dimana pasien mengalami hypernatremia dan polyuria yaitu Diabetes insipidus. Berbeda bila pasien memiliki gejala hyponatremia maka osmolalitas urin menjadi penentu dalam membedakan antara cerebral salt wasting syndrome (CSWS) dengan syndrome inappropriate antidiuretic hormone (SIADH). Desmopresin (1-deamino-8-arginine vasopressin) ini adalah adalah drug of choice untuk terapi diabetes insipidus. Desmopressin adalah sintetik analog vasopressin, sintetik dan kerja panjang yang memiliki kekuatan antidiuretik dua kali lipat dari arginine vasopressin. Biasanya dosis obat dimulai dari malam untuk menghindari gejala polyuria saat malam hari. Bila siang hari produksi urin masih tinggi dapat diberikan saat siang untuk mengendalikan gejalanya. Desmopressin dapat diberikan per oral, intranasal, sublingual dan parenteral. ${ }^{5,7}$
Pada beberapa pusat pendidikan vasopressin diberikan secara intravena. Native vasopressin adalah alternatif lain dari pemberian vasopressin. Terutama pada fase awal kesakitan karena sifat lama kerja pendek, hingga mudah dilakukan penyesuaian. Kerugiannya beberapa kajian terdahulu telah menyatakan bahwa native vasopressin membuat stimulasi pada reseptor V1 yang menyebabkan terbentuknya antibody antivasopresin. Hingga terapi yang diberikan tidak akan membawa manfaat bagi pasien. Tetapi beberapa rumah sakit malah lebih memilih penggunaan native vasopressin karena mudahnya dilakukan titrasi. ${ }^{8,10,11}$

Pada kasus ini Native vasopressin tidak diberikan. Saat fase awal onset dari central diabetes insipidus pun menggunakan desmopressin intranasal. Hal ini disebabkan karena lebih mudah pemberiannya dan lebih paham farmako dinamik dan kinetik dari desmopressin spray. Hampir pada semua jurnal menyatakan bahwa kasus diabetes insipidus pasca cedera otak traumatika bersifat transient/ sementara. Hanya $6,9 \%$ yang bersifat menetap. ${ }^{4}$ Tetapi pada kasus ini diduga menetap karena bila dosis desmopressin diturunkan atau di stop maka akan memicu kenaikan kembali dari produksi urin. Hingga akhirnya penggunaan desmopressin tetap dipertahankan dengan peroral.

\section{Simpulan}

Cedera otak traumatika adalah salah satu penyebab mortalitas dan morbiditas terbesar pada usia dewasa muda. Masalah disfungsi neuroendocrine pada pasca cedera otak traumatika yang sering terjadi adalah terkait dengan elektrolit dan air. Gangguan pada elektrolit dan air ini terkait dengan central diabetes insipidus, cerebral salt wasting syndrome dan SIADH. Tidak ada waktu yang pasti kapan central diabetes insipidus akan tampil secara klinis pada pasien cedera otak traumatika. Karena ia dapat bermanifes beberapa hari setelah trauma hingga 3 bulan setelah trauma terjadi. Mengenali gejala seperti produksi urin yang meningkat, terjadinya hypernatremia, penurunan osmolalitas urin menjadi tanda yang harus dipertimbangkan pada penegakkan diagnosis dari central diabetes insipidus. Pengelolaan central 
diabetes insipidus disamping menggunakan desmopressin spray atau oral yang tidak boleh dilupakan adalah penggantian cairan yang hilang.

\section{Daftar pustaka}

1. Tan CL, Alavi SA, Baldewag SE, Belli A, Carson A, Feeney C. The screening and management of pituitary dysfunction following traumatic brain injury in adults: British neurotrauma group guidance. J Neurol Neurosurg Psychiatry 2017;0:1-11.

2. Bondanelli M, Ambrosio MR, Zatelli MC, Marinis LD, Uberti ECD. Hypopituitarism after traumatic brain injury. European Journal of Endocrinology 2005;152:679-91.

3. Agrawal A, Reddy PA, Prasad NR. Endocrine manifestations of traumatic brain injury. The IndianJournalofNeurotrauma2015;9:123-28.

4. Agha A, Thornton E, O Kelly P, Tormey W, Phillips J, Thompson CJ. Posterior pituitary dysfunction after traumatic brain injury. J Clin Endocrinol Metab 2004;89:5987-92.

5. Capatina C, Paluzi A, Mitchell R, Karavitaki N. Diabetes insipidus after traumatic brain injury. J Clin Med 2015;4:1448-62.

6. Magbri A, Magbri EE, Hershit S. Hypernatremia and central diabetes insipidus following neurosurgical procedure of trauma.
Arch Pathol Clin Res 2017;1:005-008.

7. Saifan C, Nasr R, Mehta S, Acharya PS, Perrera I, Faddoul G. Diabetes insipidus: a challenging diagnosis with new drug therapies. ISRN Nephrology 2013; article ID797620:7 pages.

8. Rollstin A, Mason M, Green AK, Coleman L,Bui P, Marinaro J. Continuous vasopressin infusion for the management of central diabetes insipidus. SRL Neurology and Neurosurgery 2017;3(2):031-34.

9. Tritos NA, Yuen KCJ, Kelly DF. American association of clinical endocrinologist and American college of endocrinology disease state clinical review: a neuroendocrine approach to patients with traumatic brain injury. Endocr Pract 2015;21: 823-31.

10. Shukla A, Alqadri S, Ausmus A, Bell R, Nattanmai P, Newey CR. Vasopressin bolus protocol compared to desmopressin (DDAVP)for managing acute, postoperative central diabetes insipidus and hypovolemic shock. Endocrinology volume 2017, article ID 3052102, 4pages.

11. Oiso Y, Robertson GL, Norgaard JP, Juul KV. Treatment of neurohypophyseal diabetes insipidus. J Clin Endocrinol Metab 2013;98:3958-67. 